\title{
Up-regulation of the long non-coding RNA RMRP contributes to glioma progression and promotes glioma cell proliferation and invasion
}

\author{
Wenxian Feng ${ }^{1}$, Li $\mathrm{Li}^{1}$, Xuchang Xu${ }^{1}$, Yunqi Jiao ${ }^{1}$, Wei Du
}

\begin{abstract}
${ }^{1}$ Department of Neurosurgery, Zhumadian Central Hospital, Zhumadian, Henan, China 2Department of Neurosurgery, The First Affiliated Hospital of Zhengzhou University, Zhengzhou, Henan, China
\end{abstract}

Submitted: 28 June 2016

Accepted: 12 November 2016

Arch Med Sci 2017; 13, 6: 1315-1321

DOI: https://doi.org/10.5114/aoms.2017.66747

Copyright @ 2017 Termedia \& Banach

\begin{abstract}
Introduction: Gliomas are the most common malignant tumors of the brain. Long non-coding RNAs (IncRNAs) play key regulatory roles in various tumors. In this study, we aimed to determine the expression and biological roles of IncRNA RMRP in glioma.

Material and methods: The relative expression level of IncRNA RMRP was determined by quantitative real-time polymerase chain reaction (qRT-PCR) in a total of 39 patients with glioma. RNA interference (RNAi) approaches were used to investigate the biological functions of RMRP. The effect of IncRNA RMRP on proliferation was determined by CCK8 assay. Cell cycle and apoptosis were evaluated by flow cytometry analysis. Cell migration was explored by the wound-healing assay. Cell invasion was investigated by the Transwell invasion assay.

Results: LncRNA RMRP was up-regulated in human glioma tissues compared with normal brain tissues $(p<0.05)$. LncRNA RMRP up-regulation was significantly correlated with advanced tumor grade and low Karnofsky Performance Score (KPS) $(p<0.05)$. Moreover, patients with a high expression level of IncRNA RMRP had a relatively poor prognosis $(p<0.05)$. Multivariate analyses revealed that IncRNA RMRP expression served as an independent predictor for overall survival of glioma patients $(p<0.05)$. In addition, inhibition of IncRNA RMRP by RNAi significantly suppressed the proliferation, migration and invasion of glioma cells in vitro $(p<0.05)$.

Conclusions: IncRNA RMRP might act as an oncogene and could be used as a therapeutic target for the treatment of glioma. Our findings provide an indepth insight into the role of InCRNA RMRP in glioma progression.
\end{abstract}

Key words: long non-coding RNAs, RMRP, glioma, prognosis, progression.

\section{Introduction}

Glioma is one of the most common types of primary brain tumor in adults, and represents one of the most aggressive and lethal human cancer types [1]. Despite great progress in therapeutic technologies, such as surgery, radiotherapy, photodynamic therapy, and chemotherapy, the clinical outcome of patients with gliomas remains poor [2, 3]. Therefore, it is critical to understand the molecular mechanisms involved in glioma progression, to identify reliable biomarkers and therapeutic targets for glioma patients.

With the development of whole-genome sequencing technology, it was determined that less than $2 \%$ of the mammalian genome is in protein

\author{
Corresponding author: \\ Li Li \\ Department of Neurosurgery \\ Zhumadian Central Hospital \\ No. 747 West \\ Zhonghua Road \\ Zhumadian, 463500 \\ Henan, China \\ E-mail: \\ wenxianfeng0071@163.com
}


encoding regions and the remainder is in non-coding RNAs (ncRNAs) [4]. Long non-coding RNAs (IncRNAs) are a class of ncRNA transcripts longer than 200 nucleotides and are implicated in a number of important events, such as epigenetic regulation, transcriptional regulation, and post-transcriptional regulation [5, 6]. More and more evidence suggests that IncRNAs play a critical role in glioma progression and may serve as a therapeutic target. For example, Ma et al. found that IncRNA MALAT1 was increased in glioma and associated with the malignant status and poor prognosis in glioma patients [7]. Wang et al. reported that IncRNA MEG3 was decreased in glioma tissues and ectopic expression of MEG3 inhibited cell proliferation and promoted cell apoptosis in glioma cells [8]. Shi et al. showed that IncRNA H19 promoted glioma cell invasion by deriving miR-675 [9].

LnCRNA RMRP, a newly identified IncRNA, was first found to show dysregulated expression in gastric cancer [10]. Furthermore, it was demonstrated that IncRNA RMRP promoted carcinogenesis by acting as a miR-206 sponge and could be used as a novel biomarker for gastric cancer [11]. However, the prognostic role of IncRNA RMRP in cancer is still unclear, and fewer studies have examined the expression levels and underlying molecular mechanism in glioma.

In this study, we determined IncRNA RMRP expression and its correlation with clinicopathological features and prognosis in patients with glioma. Furthermore, the biological function of IncRNA RMRP was investigated in glioma cells in vitro.

\section{Material and methods}

\section{Human tissue samples}

Thirty-nine glioma tissues and 11 normal brain tissues (NBTs) were obtained from the Department of Neurosurgery, Zhumadian Central Hospital during 2010-2013. All samples had confirmed pathological diagnosis and were divided into low grade (grade I-II) and high grade (grade III-IV) according to the WHO classification by neuropathologists. Informed consent was obtained from all patients, and this study was approved by the Clinical Research Ethics Committee at the Zhumadian Central Hospital (No. Z20160501A).

\section{Cell culture}

The human glioma U87 and U251 cell lines were purchased from the Chinese Academy of Sciences (Shanghai, China). Cells were cultured in Dulbecco's modified Eagle's medium (DMEM, Life Technologies) with $10 \%$ fetal bovine serum (FBS, Life Technologies), $100 \mathrm{lU} / \mathrm{ml}$ penicillin, and $100 \mathrm{IU} /$ $\mathrm{ml}$ streptomycin at $37^{\circ} \mathrm{C}$ in a humidified atmosphere with $5 \% \mathrm{CO}_{2}$.

\section{siRNA transfection}

Cells were transfected with siRNA using Lipofectamine 2000 (Invitrogen) according to the manufacture's protocol. The sequence of siRNA for the RMRP was 5'-CCUAGGCUACACACUGAGGACUTT-3' (Si-RMRP) [11]. The sequence of negative control SiRNA (si-NC) was 5'-UUCUCCGAACGUGUCACGUTT-3' [11]. The chemically modified siRNAs were synthesized by Shanghai GenePharma.

\section{RNA extraction and quantitative real-time polymerase chain reaction}

Total RNA of tissues or cells was extracted using Trizol Reagent (Life Technologies). RNA was reversed transcribed into cDNAs using the PrimerScript one step RT-PCR kit (TaKaRa). The cDNA template was amplified by real-time RT-PCR using the SYBR Premix Dimmer Eraser kit (TaKa$\mathrm{Ra}$ ). GAPDH was used as an internal control, and RMRP values were normalized to GAPDH. qRT-PCR reactions were performed by the ABI7500 system (Applied Biosystems). The relative expression fold change of mRNAs was calculated by the $2^{-\Delta \Delta c t}$ method. The primer sequences were as follows: InCRNA RMRP: 5'-ACTCCAAAGTCCGCCAAGA-3' and 5'-GTAACTAGAGGGAGCTGAC-3'; GADPH: 5'-GTCAACGGATTTGGTCTGTATT-3' and 5'-AGTCTTCTGGGTGGCAGTGAT-3' [11].

\section{CCK8 assay}

Cells at a concentration of $5 \times 10^{3}$ per well were seeded in the 96-well plate and incubated for $12 \mathrm{~h}$, 24 h, 48 h, 72 h, 96 h. Cell proliferation viability was measured with a Cell Counting Kit-8 (CCK8, Beyotime) following the manufacturer's instructions. Absorbance was then recorded at $450 \mathrm{~nm}$ using Elx800 Reader (Bio-Tek Instruments).

\section{Flow cytometric analysis}

Cells transfected with the desired siRNA were plated in 6-well plates. After $48 \mathrm{~h}$ incubation, the cultures were incubated with propidium iodide for $30 \mathrm{~min}$ in the dark. Cultures were collected and analyzed for the cell cycle using a flow cytometer (FACSCalibur) after propidium iodide staining. The cultures were also stained with annexin V-fluorescein isothiocyanate, and the cell apoptosis was analyzed using a flow cytometer.

\section{Wound-healing assay}

Cells were plated into a 12-well plate and cultured at $37^{\circ} \mathrm{C}$ for $24 \mathrm{~h}$. Wounds were created in monolayers of cells using a $10 \mu$ l pipette tip. Cells were washed to remove cellular debris and incubated in DMEM without FBS at $37^{\circ} \mathrm{C}$. Images were taken at $48 \mathrm{~h}$ following wounding. The wound area 
was measured and the percentage of the wound healing was calculated by Image J software.

\section{Transwell invasion assay}

Cell invasion was performed using 24-well transwell plates (Corning) pre-coated with Matrigel (BD). Cells were seeded in the upper chambers of inserts at a density of $5 \times 10^{4}$ cells per well with serum-free DMEM. DMEM supplement with $10 \%$ serum was added to lower chambers. After being cultured for $48 \mathrm{~h}$, invasion cells were stained by violet crystalline solution according to the protocol. In order to count cell numbers in five random fields, phase contrast microscopy was employed.

\section{Statistical analysis}

All statistical analyses were performed with SPSS 18.0. Data are expressed as mean \pm SD. Stu- dent's $t$-test or one-way ANOVA was used to analyze the differences among groups. $P$-value $<0.05$ was considered to be statistically significant.

\section{Results}

\section{IncRNA RMRP expression} and clinicopathologic features in glioma

Expression levels of IncRNA RMRP in 39 glioma tissues and 11 normal brain tissues were examined by quantitative real-time PCR (qRT-PCR). qRT-PCR data showed that IncRNA RMRP was significantly increased in glioma tissues compared with normal brain tissues (Figure 1 A, $p<0.05$ ). Furthermore, correlation of IncRNA RMRP expression with clinicopathologic features of glioma patients revealed a significant association between IncRNA RMRP up-regulation with advanced tumor grade and low Karnofsky Performance Score (KPS) (Figures $1 \mathrm{~B}$ and $\mathrm{C}, p<0.05)$. Those data indicated
A

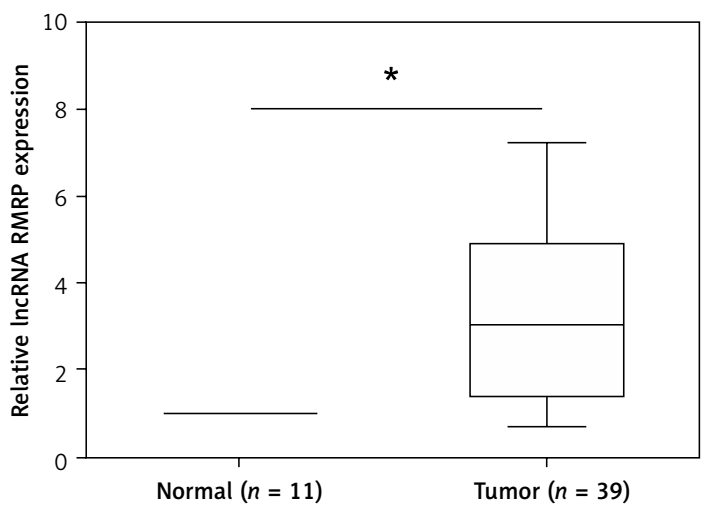

C

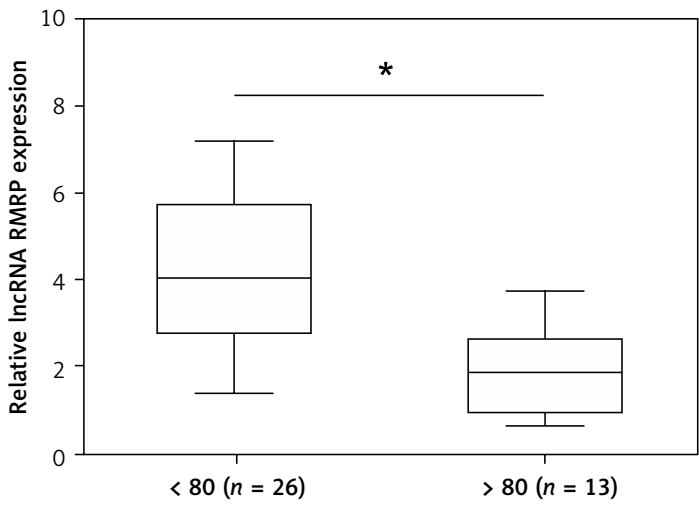

B

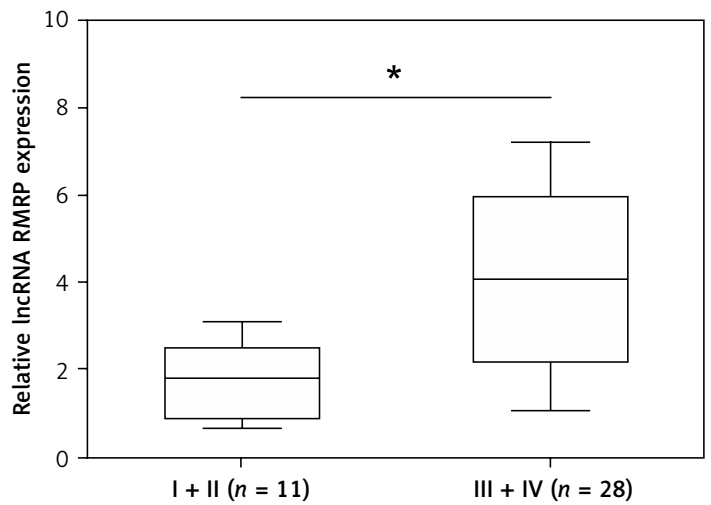

D

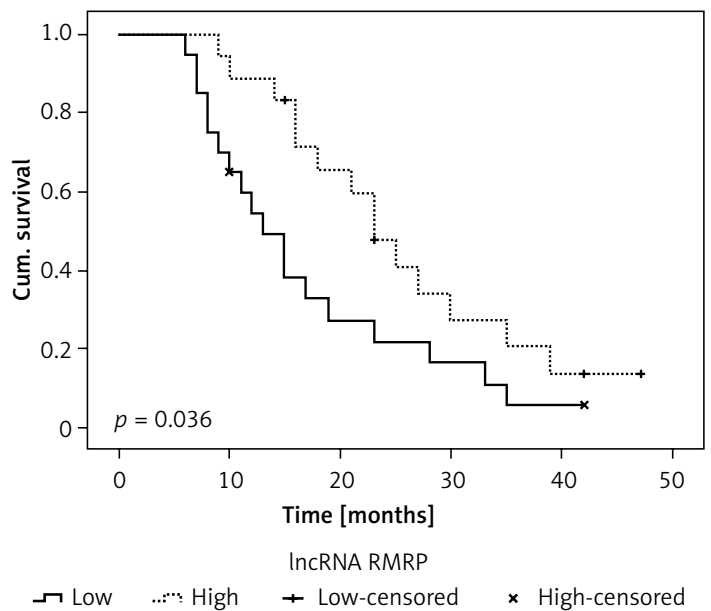

Figure 1. Relative IncRNA RMRP expression level in glioma tissues and its clinical significance. A - IncRNA RMRP was detected in 39 glioma tissues and 11 normal brain tissues by qRT-PCR. Data are presented as fold change in tumor tissues relative to normal tissues. B - IncRNA RMRP expression was significantly higher in patients at advanced tumor stages. C - IncRNA RMRP expression was significantly higher in patients with low KPS. D - Patients with high levels of IncRNA RMRP expression showed reduced survival times compared with patients with a low expression level of IncRNA RMRP (log-rank test, $p<0.05$ )

${ }^{*} P<0.05$. 
that IncRNA RMRP up-regulation may be involved in glioma progression.

We divided the 39 glioma patients into a high expression group $(n=19)$ and a low expression group $(n=20)$ according to the median expression level of IncRNA RMRP. Clinicopathologic features were analyzed in the high and low expression groups (Table I). Our data showed that high RMRP expression was observed to be closely correlated with advanced tumor grade and low KPS. However, there were no significant correlations between IncRNA RMRP expression and other clinicopathologic features, such as patients' age, gender, and tumor size (Table I, $p>0.05$ ).

\section{Statistical analysis}

Kaplan-Meier survival analysis and the logrank test using patient post-operative survival were performed to further evaluate the correlation between IncRNA RMRP expression and glioma patients' prognosis. We found that overall survival of the high IncRNA RMRP expression group was significantly poorer than that of the low IncRNA RMRP expression group (Figure $1 \mathrm{D}$, $p<0.05)$. Moreover, multivariate analysis demonstrated that IncRNA RMRP expression was an independent prognostic indicator for overall survival of glioma patients (Table II, $p<0.05$ ). Thus, these results suggested that IncRNA RMRP might have important roles in glioma progression and development.

\section{Knockdown of IncRNA RMRP inhibits} glioma cell proliferation in vitro

To further investigate the function of RMRP in glioma cells, RMRP siRNA was transfected into U87 and U251 cell lines. To avoid off-target effects and ensure the efficiency of interference, we used an interference target sequence of RMRP validated as effective according to a previous study [11] qRT-PCR showed that IncRNA RMRP expression was significantly reduced both in U87 and U251 cell lines (Figure $2 \mathrm{~A}, p<0.05$ ). Then the CCK8 assay showed that knockdown of IncRNA RMRP expression significantly inhibited cell proliferation both in U87 and U251 cell lines compared with the negative control group (si-NC) (Figure $2 \mathrm{~B}$, $p<0.05)$. Next, flow cytometric analysis was used to explore whether RMRP affected cell proliferation by altering cell cycle progression or apoptosis. We found that decreased expression of IncRNA RMRP significantly stalled glioma cells at the G1/G0 phase and induced glioma cell apoptosis (Figure $2 \mathrm{C}$ and $\mathrm{D}, p<0.05$ ). These data suggested that down-regulated expression of IncRNA RMRP might inhibit glioma cell proliferation via arresting cells in G0/G1 phase and induce cell apoptosis.

\section{Knockdown of IncRNA RMRP inhibits} glioma cell migration and invasion

The wound-healing assay and Transwell invasion assay were performed to assess the effect of

Table I. Association of IncRNA RMRP expression with clinicopathological features of glioma patients

\begin{tabular}{|c|c|c|c|c|c|}
\hline \multirow{2}{*}{$\begin{array}{l}\text { Clinicopathological } \\
\text { features }\end{array}$} & \multirow[t]{2}{*}{ Group } & \multirow[t]{2}{*}{ Total } & \multicolumn{2}{|c|}{ IncRNA RMRP expression } & \multirow[t]{2}{*}{$P$-value } \\
\hline & & & Low & High & \\
\hline \multirow[t]{2}{*}{ Gender } & Male & 23 & 12 & 11 & \multirow[t]{2}{*}{0.894} \\
\hline & Female & 16 & 8 & 8 & \\
\hline \multirow[t]{2}{*}{ Age [years] } & $<50$ & 15 & 7 & 8 & \multirow[t]{2}{*}{0.648} \\
\hline & $\geq 50$ & 24 & 13 & 11 & \\
\hline \multirow[t]{2}{*}{ Tumor size $[\mathrm{cm}]$} & $<5$ & 22 & 9 & 13 & \multirow[t]{2}{*}{0.140} \\
\hline & $\geq 5$ & 17 & 11 & 6 & \\
\hline \multirow[t]{2}{*}{ WHO grade } & $|+| \mid$ & 11 & 9 & 2 & \multirow[t]{2}{*}{0.017} \\
\hline & $I I I+I V$ & 28 & 11 & 17 & \\
\hline \multirow[t]{2}{*}{ KPS } & $<80$ & 26 & 10 & 16 & \multirow[t]{2}{*}{0.023} \\
\hline & $\geq 80$ & 13 & 10 & 3 & \\
\hline
\end{tabular}

Table II. Multivariate analysis of overall survival in glioma patients

\begin{tabular}{|lccc|}
\hline Clinicopathological features & \multicolumn{3}{c|}{ Multivariate analysis } \\
\cline { 2 - 4 } & Hazard ratio & $95 \% \mathrm{Cl}$ & $P$-value \\
\hline Tumor grade & 2.837 & $1.37-8.893$ & 0.015 \\
\hline KPS & 1.872 & $1.105-5.297$ & 0.019 \\
\hline InCRNA RMRP & 2.319 & $1.417-7.296$ & 0.007 \\
\hline
\end{tabular}


A

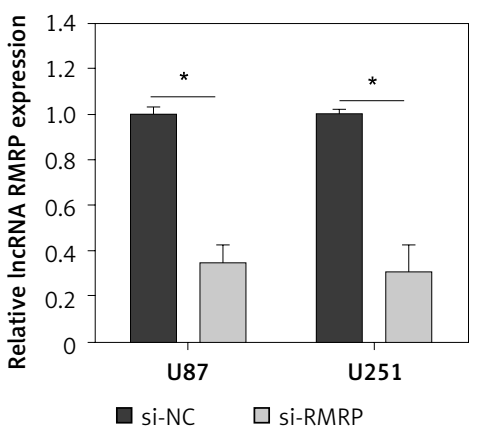

C

U87
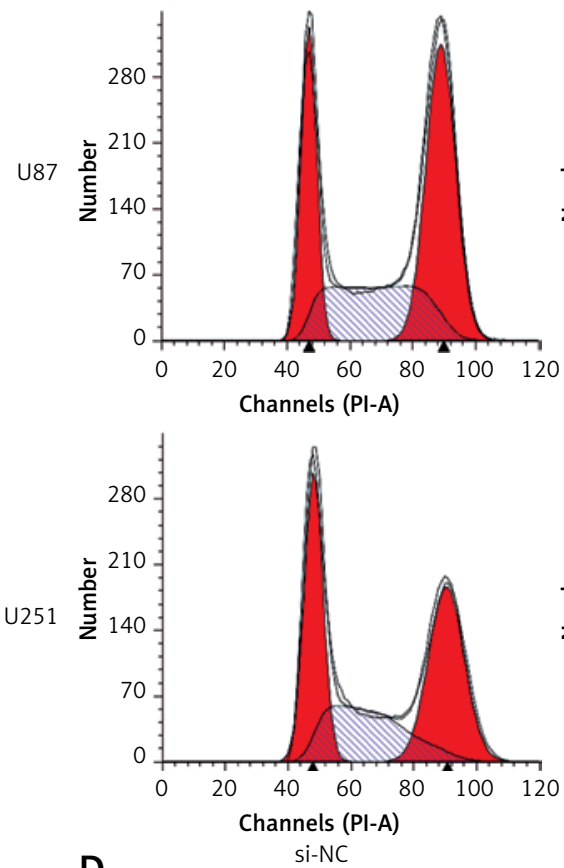

D
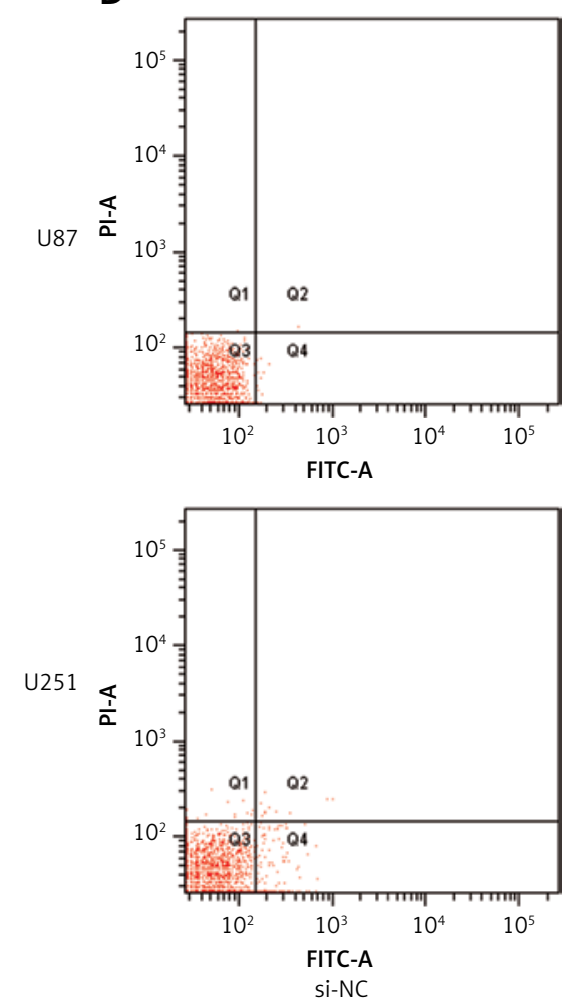

B
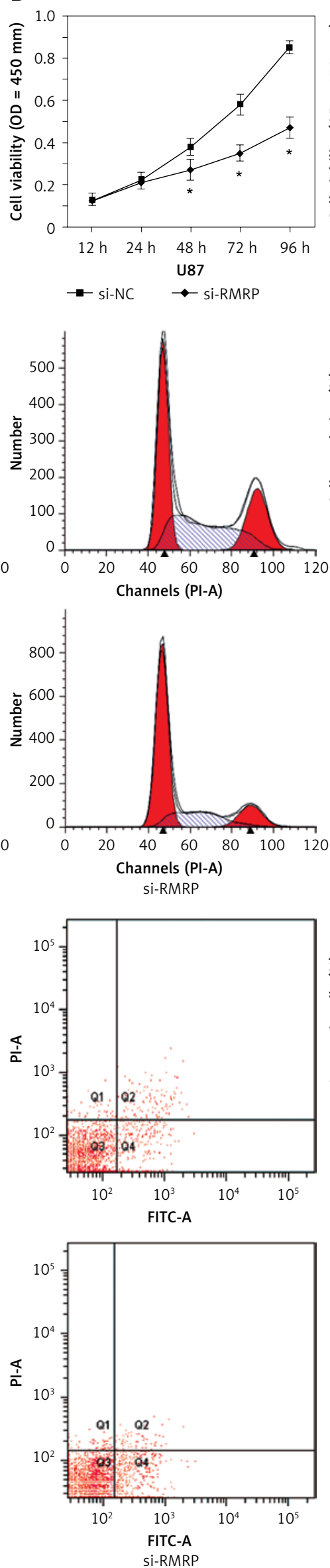
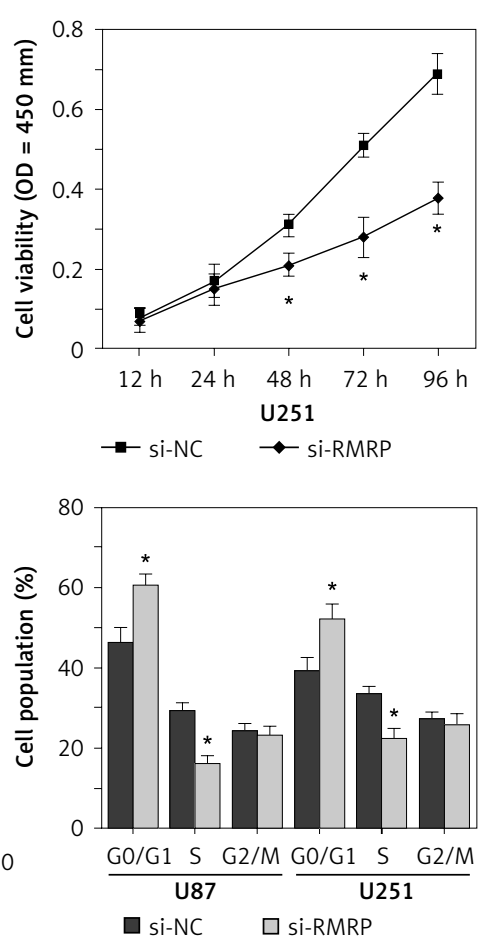

$\square$ si-NC $\square$ si-RMRP

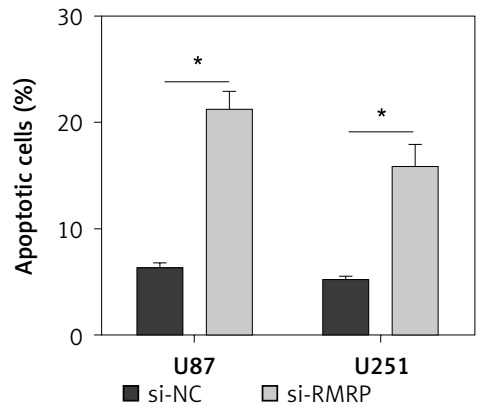

Figure 2. Knocked-down IncRNA RMRP expression inhibited glioma cell proliferation in vitro. $\mathbf{A}-$ The relative expression level of IncRNA RMRP in U87 and U251 cells was decreased by IncRNA RMRP specific siRNAs (si-RMRP) compared with the si-NC group. B - CCK8 assay was performed to determine the proliferation of si-RMRP transfected U87 and $\mathrm{U} 251$ cells. $\mathbf{C}$ - Cell cycle assay was performed to determine the cell cycle of si-RMRP transfected U87 and U251 cells. D - Cell apoptosis assay was used to explore the apoptosis of si-RMRP transfected U87 and U251 cells ${ }^{*} P<0.05$. 
IncRNA RMRP on the invasiveness of glioma cells. The wound-healing assay showed that U87 and U251 cells transfected with si-RMRP displayed lower migration capacity than the si-NC group (Figure $3 \mathrm{~A}, p<0.05$ ). The Transwell invasion assay indicated that the invasion ability of si-RMRP transfected U87 and U251 cells was reduced compared to the si-NC group (Figure $3 \mathrm{~B}, p<0.05$ ). These findings demonstrated that down-regulated IncRNA RMRP expression might suppress the migration and invasion ability of glioma cells.

\section{Discussion}

LncRNA dysregulation may affect epigenetic information and provide a cellular growth advan- tage, resulting in progressive and uncontrolled tumor growth [12, 13]. Effective control of both cell survival and cell proliferation is critical to the prevention of oncogenesis and to successful cancer therapy [14]. Therefore, identification of cancer associated IncRNAs and investigation of their clinical significance and functions may provide a missing piece of the well-known oncogenic and tumor suppressor network puzzle.

The RNA component of mitochondrial RNA processing endoribonuclease (RMRP), a IncRNA, was first discovered in cartilage-hair hypoplasia $(\mathrm{CHH})$, an autosomal recessive inherited disease [15]. RMRP is primarily identified in the nucleus, nucleolus and mitochondria [16]. It is high-

A

U87
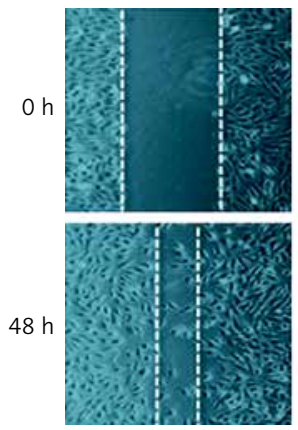

si-NC
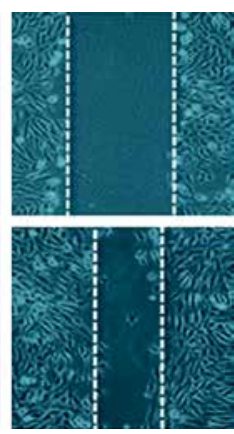

Si-RMRP

B

U87
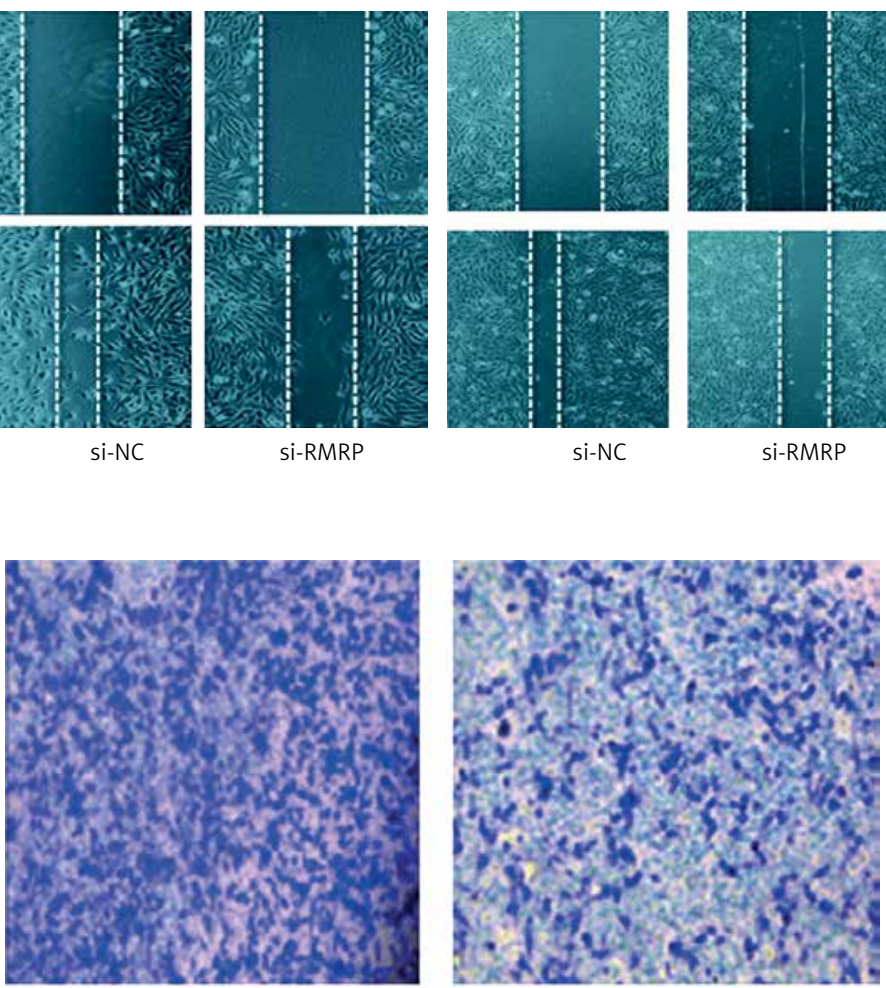

si-NC
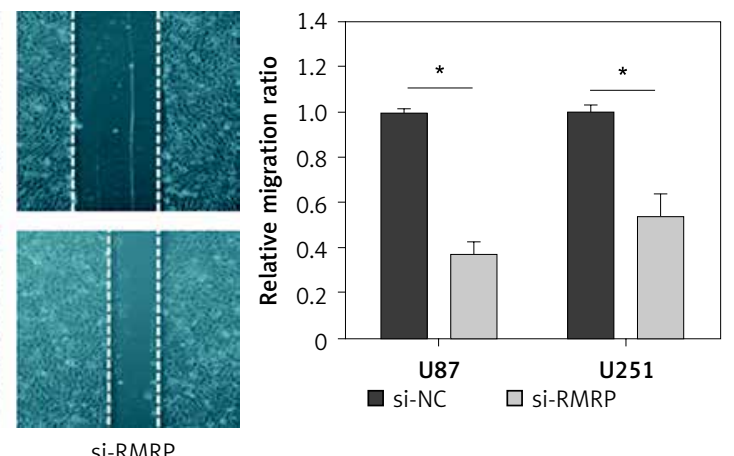

$\square$ si-NC $\square$ si-RMRP

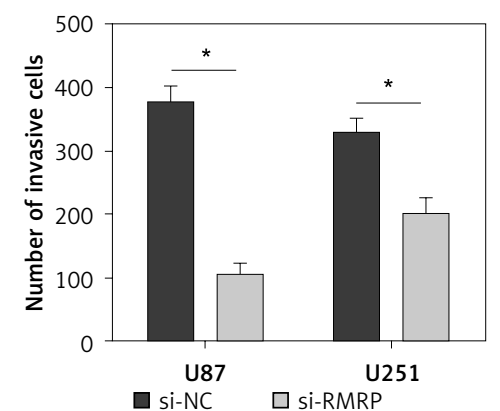

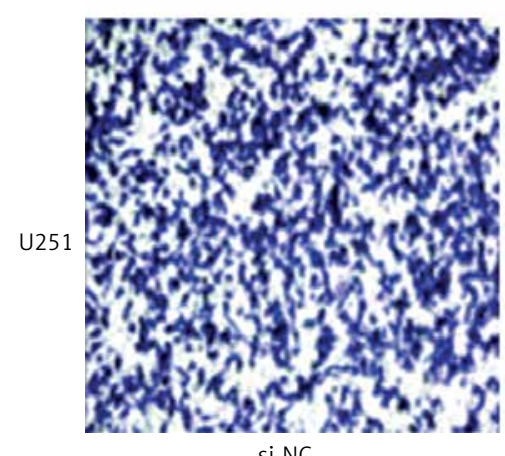

si-NC

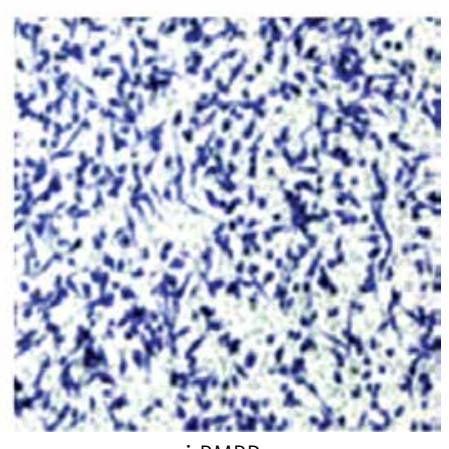

Si-RMRP

Figure 3. Decreased expression of IncRNA RMRP suppressed glioma cell migration and invasion in vitro. A - Wound-healing assay was used to explore the migration ability of si-RMRP transfected U87 and U251 cells. B - Transwell invasion assay was used to determine the invasion capacity of si-RMRP transfected U87 and U251 cells ${ }^{*} P<0.05$. 
ly expressed in a wide range of human tissues and is essential for development at early stages of embryogenesis [17]. In mitochondria, RMRP helps endonuclease to cleave mitochondrial RNA at a priming site of mitochondrial DNA replication [18]. While in nucleoli, RMRP carries out an essential function in the final step of $5.8 \mathrm{~S}$ rRNA processing [19]. Recent studies showed that knockdown of RMRP significantly inhibited cell proliferation in vitro and in vivo. Acting as a miR206 sponge, RMRP modulated the cell cycle by regulating cyclin D2 expression. It was suggested that RMRP plays a crucial role in gastric cancer occurrence and could be used as a novel biomarker for gastric cancer [11]. However, the function of IncRNA RMRP in the development and progression of glioma remains unclear.

In the present study, our data showed that IncRNA RMRP was up-regulated in glioma tissues compared to normal brain tissues. The high expression level of IncRNA RMRP in glioma was correlated with advanced tumor grade and low KPS. Furthermore, the up-regulated expression of IncRNA RMRP in glioma was associated with poor prognosis. Multivariate analysis revealed that IncRNA RMRP expression level could serve as a prognostic indicator in glioma patients. These findings indicated that IncRNA RMRP played a direct role in the modulation of cancer progression, and might be useful as a novel prognostic or progression biomarker for glioma.

To further explore the biological function of IncRNA RMRP in glioma, we determined the effects of loss of function of IncRNA RMRP on various aspects of glioma biology. The CCK8 assay showed that knockdown of IncRNA RMRP significantly decreased the proliferation ability of glioma cells in vitro. Flow cytometric analysis showed that decreased expression of IncRNA RMRP stalled glioma cells at the G1/G0 phase and induced glioma cell apoptosis. In addition, the wound-healing assay and Transwell invasion assay revealed that knockdown of IncRNA RMRP significantly reduced the metastasis capability of glioma cells in vitro. Those findings suggested that a decreased expression level of IncRNA RMRP might inhibit the malignant phenotypes of glioma cells, including cell proliferation, migration and invasion.

In conclusion, in the present study, we demonstrated that IncRNA RMRP was overexpressed in glioma and could be considered as an independent prognostic biomarker in glioma patients. IncRNA RMRP played a key role in the progression of glioma by regulating cell proliferation and metastasis. Our findings demonstrated that InCRNA RMRP could be a prognostic biomarker and therapeutic target for the treatment of glioma in future.

\section{Acknowledgments}

The project was supported by the key scientific and technological plan funding project of Zhumadian Central Hospital (No. 16604).

\section{Conflict of interest}

The authors declare no conflict of interest.

\section{References}

1. Jemal A, Bray F, Center MM, et al. Global cancer statistics. CA Cancer J Clin 2011; 61: 69-90.

2. Schwartzbaum JA, Fisher JL, Aldape KD, et al. Epidemiology and molecular pathology of glioma. Nature Clin Pract Neurol 2006; 2: 494-503.

3. Milano MT, Johnson MD, Sul J, et al. Primary spinal cord glioma: a surveillance, epidemiology, and end results database study. J Neurooncol 2010; 98: 83-92.

4. Mattick JS, Makunin IV. Non-coding RNA. Hum Mol Genet 2006; 15 (Suppl 1): R17-29.

5. Mercer TR, Dinger ME, Mattick JS. Long non-coding RNAs: insights into functions. Nature Rev Genet 2009; 10: 155-9.

6. Fatica A, Bozzoni I. Long non-coding RNAs: new players in cell differentiation and development. Nature Rev Genet 2014; 15: 7-21.

7. Ma K, Wang H, Li X, et al. Long noncoding RNA MALAT1 associates with the malignant status and poor prognosis in glioma. Tumor Biol 2015; 36: 3355-9.

8. Wang P, Ren Z, Sun P. Overexpression of the long non-coding RNA MEG3 impairs in vitro glioma cell proliferation. J Cell Biochem 2012; 113: 1868-74.

9. Shi Y, Wang Y, Luan W, et al. Long non-coding RNA H19 promotes glioma cell invasion by deriving miR-675. PLoS One 2014; 9: e86295.

10. Song $H$, Sun W, Ye G, et al. Long non-coding RNA expression profile in human gastric cancer and its clinical significances. J Transl Med 2013; 11: 225.

11. Shao Y, Ye M, Li Q, et al. LncRNA-RMRP promotes carcinogenesis by acting as a miR-206 sponge and is used as a novel biomarker for gastric cancer. Oncotarget 2016; 7: 37812-24.

12. Lee JT. Epigenetic regulation by long noncoding RNAs. Science 2012; 338: 1435-9.

13. Mercer TR, Mattick JS. Structure and function of long noncoding RNAs in epigenetic regulation. Nat Struct Mol Biol 2013; 20: 300-7.

14. Evan GI, Vousden KH. Proliferation, cell cycle and apoptosis in cancer. Nature 2001; 411: 342-8.

15. Rogler LE, Kosmyna B, Moskowitz D, et al. Small RNAs derived from IncRNA RNase MRP have gene-silencing activity relevant to human cartilage-hair hypoplasia. Hum Mol Genet 2014; 23: 368-82.

16. Li K, Smagula CS, Parsons WJ, et al. Subcellular partitioning of MRP RNA assessed by ultrastructural and biochemical analysis. J Cell Biol 1994; 124: 871-82.

17. Rosenbluh J, Nijhawan D, Chen Z, et al. RMRP is a noncoding RNA essential for early murine development. PloS One 2011; 6: e26270.

18. Chang DD, Clayton DA. A novel endoribonuclease cleaves at a priming site of mouse mitochondrial DNA replication. EMBO J 1987; 6: 409.

19. Schmitt ME, Clayton DA. Nuclear RNase MRP is required for correct processing of pre-5.8 S rRNA in Saccharomyces cerevisiae. Mol Cell Biol 1993; 13: 7935-41. 